Research article

\title{
Long-term prognostic significance of HER-2/neu in untreated node-negative breast cancer depends on the method of testing
}

\author{
Marcus Schmidt ${ }^{1}$, Barbara Lewark ${ }^{1}$, Nikolai Kohlschmidt ${ }^{2}$, Christiane Glawatz ${ }^{1}$, Erik Steiner ${ }^{1}$, \\ Berno Tanner ${ }^{1}$, Henryk Pilch ${ }^{1}$, Wolfgang Weikel ${ }^{1}$, Heinz Kölbl ${ }^{1}$ and Hans-Anton Lehr ${ }^{2}$
}

\author{
1Department of Obstetrics and Gynecology, Johannes Gutenberg University, Medical School, Mainz, Germany \\ 2Department of Pathology, Johannes Gutenberg University, Medical School, Mainz, Germany \\ Corresponding author: Marcus Schmidt, MarcusSchmidtMD@aol.com
}

Received: 8 Sep 2004 Revisions requested: 3 Nov 2004 Revisions received: 21 Nov 2004 Accepted: 15 Dec 2004 Published: 26 Jan 2005

Breast Cancer Res 2005, 7:R256-R266 (DOI 10.1186/bcr991)

(C) 2005 Schmidt et al.; licensee BioMed Central Ltd.

This is an Open Access article distributed under the terms of the Creative Commons Attribution License (http://creativecommons.org/licenses/by/ 2.0), which permits unrestricted use, distribution, and reproduction in any medium, provided the original work is properly cited.

\begin{abstract}
Introduction The prognostic significance of HER-2/neu in breast cancer is a matter of controversy. We have performed a study in 101 node-negative breast cancer patients with longterm follow-up not treated in the adjuvant setting, and analysed the prognostic significance of immunohistochemistry $(\mathrm{IHC})$ and fluorescence in situ hybridisation (FISH), both separately and in combination, in comparison with traditional prognostic factors.

Methods Overexpression was classified semiquantitatively according to a score (0 to 3+) (HER-2_SCO). FISH was used to analyse HER2/neu amplification (HER-2_AMP). Patients classified $2+$ by IHC were examined with $\mathrm{FISH}$ for amplification (HER-2_ALG). Patients with 3+ overexpression as well as amplification of HER-2/neu were positive for the combined variable HER2_COM. These variables were compared with tumour size, histological grade and hormone receptor status.
\end{abstract}

Results HER-2_SCO was $3+$ in $20 \%$ of all tumours. HER2_ALG was positive in $22 \%$ and amplification (HER-2_AMP) was found in $17 \%$ of all tumours. Eleven percent of the tumours showed simultaneous $3+$ overexpression and amplification. Only histological grade (relative risk [RR] 3.22, 95\% confidence interval [Cl] 1.73-5.99, $P=0.0002$ ) and HER-2_AMP (RR $2.47,95 \% \mathrm{Cl} 1.12-5.48, P=0.026$ ) were significant for disease-free survival in multivariate analysis. For overall survival, both histological grade (RR 3.89, 95\% Cl 1.77-8.55, $P=$ 0.0007 ) and HER-2_AMP (RR 3.08, 95\% Cl 1.24-7.66, $P=$ $0.016)$ retained their independent significance.

Conclusion The prognostic significance of HER-2/neu in nodenegative breast cancer depends on the method of testing: only the amplification of HER-2/neu is an independent prognostic factor for the long-term prognosis of untreated node-negative breast cancer.

\section{Introduction}

Human epidermal growth factor receptor-2 is a proto-oncogene that encodes a cell-surface receptor designated HER-2/neu or c-erbB-2. Gene amplification and/or protein overexpression occurs in 14-30\% of all breast cancers [13]. Initially, the adverse prognostic impact of HER-2/neu in breast cancer was the main focus of research. However, results from different study groups were not entirely consistent. Studies that supported the initially reported adverse prognosis in breast cancer $[1,3]$ were later followed by reports that failed to show any association with prognosis $[4,5]$. Although no consensus exists concerning the prognostic value of HER-2/neu, an increasing quantity of data indicates a predictive value for the efficacy of cer- tain adjuvant therapies. The response of HER-2/neu-positive breast cancer patients to tamoxifen is significantly worse than for HER-2/neu-negative patients $[6,7]$ even though this point of view is not unopposed $[8,9]$. More recently, it was shown that aromatase inhibitors might provide more benefit than tamoxifen in patients with tumours positive for erbB-1 and/or erbB-2 [10].

However, the strongest evidence for a predictive role for HER-2/neu comes from several retrospective trials that consistently showed that HER-2/neu-positive patients responded better to an anthracycline-based therapy than to treatment with cyclophosphamide, methotrexate and fluorouracil [11-13]. Because of this predictive impact of HER- 
2/neu, many of the studies on the prognostic role of HER$2 / n e u$ cannot be reliably interpreted when the patients enrolled were treated in an adjuvant setting. To avoid this potential bias, we have performed a retrospective study on the prognostic impact of HER-2/neu in a historical cohort of node-negative T1/T2 breast cancer patients who were at that time not being treated in an adjuvant setting.

A point of utmost importance when assessing the utility of HER-2/neu as a prognostic factor is the technique of HER$2 / n e u$ testing. Principally, gene-based assays such as Southern blot analysis or fluorecence in situ hybridisation (FISH) have to be distinguished from assays that assess the level of protein expression, such as western blot analysis or immunohistochemistry $(\mathrm{IHC})$. When analysing the published studies of HER-2/neu as a prognostic factor with regard to the technique used, Ross and colleagues [14,15] found that those studies that applied FISH to the assessment of gene amplification found an association of HER-2/ neu with the prognosis of the patients, whereas studies that used IHC for the assessment of protein expression gave rather ambiguous results. Reasons for the apparently worse performance of IHC than that of FISH could be differences in the sensitivity of the applied antibodies [16] or the lack of a uniform scoring system in most of the older studies that used IHC. Standardisation of HER-2/neu testing has received considerably more attention in recent years owing to the advent of trastuzumab, a monoclonal antibody that affords prolonged survival in patients with metastatic breast cancer [17]. To improve the quality of IHC when testing for HER-2/neu status before starting a therapy with trastuzumab, a standardised scoring protocol was developed. On the basis of these findings, an algorithm incorporating FISH only in doubtful cases (2+ in IHC) was introduced.

The aim of our present study on 101 node-negative breast cancer cases was to compare gene amplification by FISH with protein expression by $\mathrm{IHC}$ with the standardised scoring system, the above-mentioned algorithm and the combination of HER-2/neu overexpression and amplification in the prognostic value of HER-2/neu.

\section{Methods \\ Patients}

The study cohort consisted of 101 lymph-node-negative breast cancer patients who were treated at the Department of Obstetrics and Gynecology of the Johannes Gutenberg University Mainz between 1988 and 1993. Patients were all treated with surgery and did not receive any systemic therapy in the adjuvant setting. The established prognostic factors (tumour size, histological grade and steroid receptor status) were collected from the original pathology reports of the gynaecological pathology division within our department.
Patients were treated either with modified radical mastectomy $(n=58)$ or breast-conserving surgery followed by irradiation $(n=43)$. Because the administration of adjuvant systemic therapy was not allowed in this study, we focused on node-negative breast cancer patients with pT1 and pT2 tumours and without any evidence of metastasis at the time of surgery. The median age of the patients at surgery was 56 years (range $29-86$ years).

The median time of follow-up was 131 months for the patients still alive at the time of analysis. Within this followup period, 31 patients relapsed, 20 patients died of breast cancer and 10 patients died of unrelated causes. The patients dying of causes other than breast cancer were censored for the survival analyses at their date of death.

\section{HER-2/neu amplification determined by FISH}

FISH for HER-2/neu gene amplification was performed with the Appligene Oncor HER-2/neu gene amplification system (Ventana Medical Systems, Tucson, AZ, USA), following the supplier's instructions. In brief, fresh frozen slides were first treated with a protein-digesting enzyme at $37^{\circ} \mathrm{C}$ for $10 \mathrm{~min}$, washed in $2 \times$ sodium chloride/sodium citrate (SSC) at $22^{\circ} \mathrm{C}$, dehydrated in an $75-100 \%$ ethanol series and air dried. Tissue sections were than denatured for $5 \mathrm{~min}$ in $70 \%$ formamide, $\mathrm{pH} 7.5$, at $75^{\circ} \mathrm{C}$, followed by rinsing with 100\% ethanol and air drying. Appligene Oncor HER-2/neu DNA probe was prewarmed for 5 min at $37^{\circ} \mathrm{C}$ before application. Slides were than incubated for 24 hours at $37^{\circ} \mathrm{C}$ in a humidified chamber. After hybridisation, the slides were washed in $2 \times \mathrm{SSC}$ for $5 \mathrm{~min}$ at $72^{\circ} \mathrm{C}$; this was then followed by a wash in phosphate-buffered detergent (Oncor, Gaithersburg, MD, USA) at room temperature for 5 min. Detection was achieved with the Appligene Oncor fluorescein-labelled anti-digoxigenin antibody (Ventana Medical Systems). The slides were incubated with this antibody for $5 \mathrm{~min}$ in a humidified chamber at $37^{\circ} \mathrm{C}$. Slides were then subjected to three washes ( 2 min each) in phosphate-buffered detergent at room temperature and were stored in the dark at $-20^{\circ} \mathrm{C}$ for up to 5 days before analysis. The nuclei were counterstained with a propidium iodide/antifade solution (Oncor, Gaithersburg, MD, USA). Appropriate positive controls were included in each staining run. A serial section of each slide used for FISH was stained with haematoxylin and eosin to control for the presence of invasive tumour formations.

Additionally, serial sections ( $6 \mu \mathrm{m}$ thick) of formalin-fixed paraffin-embedded blocks from five randomly selected amplified and five randomly selected non-amplified tumours were deparaffinised and then subjected to the staining protocol outlined above. 


\section{Interpretation of FISH results}

Analysis was performed with an Axioskop fluorescence microscope (Zeiss, Jena, Germany). Images were captured with an analogue camera (Leica, Bensheim, Germany). In each quadrant of the slide, the number of fluorescein signals was counted in 20 nuclei of invasive tumour cells (that is, a total of 80 tumour nuclei). Cases were considered amplified if the mean number of fluorescence signals was greater than four (HER2_AMP) [18]. Additionally, we compared tumours with low-level amplification (five or six signals per nucleus) against tumours with a higher level of amplification (more than six signals per nucleus).

\section{HER-2/neu expression determined by IHC}

The immunohistochemical staining with a monoclonal antibody against HER-2/neu was performed as described previously [19]. In brief, serial sections ( $4 \mu \mathrm{m}$ thick) of formalinfixed, paraffin-embedded blocks were first deparaffinised. They were then microwaved in $10 \mathrm{mM}$ citrate buffer, $\mathrm{pH}$ 6.0 , to unmask epitopes and treated for $10 \mathrm{~min}$ with $1 \%$ hydrogen peroxide to block endogenous peroxidase. The sections were incubated for $30 \mathrm{~min}$ at $37^{\circ} \mathrm{C}$ with monoclonal HER-2/neu antibodies (clone CB-11; Novocastra, Newcastle upon Tyne, UK) diluted 1:50. The sections were then incubated with a biotin-labelled secondary antibody and streptavidin-peroxidase for $20 \mathrm{~min}$ each. Tissue was subsequently treated for $5 \mathrm{~min}$ with $0.05 \%$ 3',3-diaminobenzidine tetrahydrochloride and lightly counterstained with haematoxylin. All series included appropriate positive and negative controls. All controls gave adequate results.

\section{Interpretation of IHC results}

Only cases showing unequivocal staining of membranes were regarded as positive for HER-2/neu overexpression [2]. A score was determined in accordance with the criteria used in the approval trials for trastuzumab [17,20]. In brief, cases showing no staining were scored 0 , cases with less than $10 \%$ membrane staining $1+$, cases with more than $10 \%$ weak to moderate complete membrane staining $2+$, and cases with more than $10 \%$ strong complete membrane staining 3+ (HER2_SCO). Only 3+ cases were considered positive for survival analyses.

\section{Interpretation of combined IHC and FISH results}

Cases that were scored $2+$ by IHC were considered positive for the HER-2/neu algorithm [21] only if they showed an amplification of HER-2/neu (HER2_ALG).

Finally, cases showing HER-2/neu amplification as well as overexpression with an immunohistochemical score of 3+ were considered positive for the combined HER-2/neu evaluation (HER2_COM).

\section{Statistical analysis}

The concordance between two methods was assessed by using the kappa test. The sensitivity and specificity of IHC (HER2_SCO) were evaluated, with the use of FISH as reference method. Life tables were calculated in accordance with the Kaplan-Meier method. Disease-free survival (DFS) was computed from the date of diagnosis to the date of recurrence of disease. Overall survival (OS) was computed from the date of diagnosis to the date of death from breast cancer. Patients who died of an unrelated cause were censored at the date of death. Survival curves were compared with the log-rank test. Univariate Cox survival analyses were performed and multivariate analyses were done in a backward stepwise fashion with the Cox proportional hazards model. All tests were performed at a significance level of $\alpha$ $=0.05$. All $P$ values are two-sided.

\section{Results \\ Distribution of traditional and HER-2/neu-related factors}

In a group of 101 node-negative patients with primary breast cancer of sizes T1 and T2 without systemic treatment in the adjuvant setting, established pathological and clinical parameters (tumour size, histological grade, steroid hormone receptor status, age and menopausal status) and HER-2/neu-related parameters (HER2_AMP, HER2_SCO, HER2_ALG and HER2_COM) were assessed and are presented in Table 1; 36\% of the patients were premenopausal and perimenopausal. Tumour size was T1 in $57 \%$ and T2 in the remaining $43 \%$. A total of $64 \%$ of the patients had tumours with a positive steroid hormone receptor status; that is, they were oestrogen receptor and/or progesterone receptor positive. A favourable histological grade (G I) was present in 17\%, G II in 58\% and G III in 20\%. Five percent had medullary carcinomas and were therefore not assigned a histological grade.

HER-2/neu overexpression classified as 3+ as assessed by IHC was found in 20\% (HER2_SCO); 17\% of tumours showed an amplification of HER-2/neu by $\mathrm{FISH}$ (HER2_AMP). Of the amplified cases, five tumours showed five or six signals per nucleus, indicating low-level amplification, and 12 tumours showed more than six signals per nucleus (evidence of a higher level of amplification). Two of the patients who were scored as $2+$ by $\mathrm{IHC}$ also exhibited an amplification of HER-2/neu. This resulted in a total of $22 \%$ of the patients being positive for HER2_ALG. Finally, in $11 \%$ of the patients an amplification as well as a $3+$ overexpression of HER-2/neu was found (HER2_COM).

The estimated DFS was $70 \%$ and the breast cancer-specific OS was $80 \%$ at 10 years for the whole group of patients. 
Table 1

Clinicopathological characteristics of 101 patients with node-negative primary breast cancer

\begin{tabular}{|c|c|c|}
\hline Characteristic & $n$ & $\%$ \\
\hline \multicolumn{3}{|l|}{ Age at diagnosis } \\
\hline Less than 50 & 36 & 36 \\
\hline More than 50 & 65 & 64 \\
\hline \multicolumn{3}{|l|}{ Menopausal status } \\
\hline Pre/perimenopausal & 36 & 36 \\
\hline Postmenopausal & 65 & 64 \\
\hline \multicolumn{3}{|l|}{ pT stage } \\
\hline pT1a,b & 16 & 16 \\
\hline $\mathrm{pT} 1 \mathrm{c}$ & 42 & 42 \\
\hline pT2 & 43 & 43 \\
\hline \multicolumn{3}{|l|}{ Histological grade } \\
\hline Gl & 17 & 17 \\
\hline Gll & 59 & 58 \\
\hline GIII & 20 & 20 \\
\hline Not done (medullary carcinomas) & 5 & 5 \\
\hline \multicolumn{3}{|l|}{ Steroid hormone receptor status } \\
\hline Positive & 65 & 64 \\
\hline Negative & 36 & 36 \\
\hline \multicolumn{3}{|l|}{ HER2_SCO } \\
\hline $0,1+$ & 63 & 62 \\
\hline $2+$ & 18 & 18 \\
\hline $3+$ & 20 & 20 \\
\hline \multicolumn{3}{|l|}{ HER2_AMP } \\
\hline Positive & 17 & 17 \\
\hline Negative & 84 & 83 \\
\hline \multicolumn{3}{|l|}{ HER2_ALG } \\
\hline Positive & 22 & 22 \\
\hline Negative & 79 & 78 \\
\hline \multicolumn{3}{|l|}{ HER2_COM } \\
\hline Positive & 11 & 11 \\
\hline Negative & 90 & 89 \\
\hline
\end{tabular}

Concordance of amplification status in formalin-fixed paraffin-embedded tumour samples with fresh-frozen tumour samples

All five tumours amplified for HER-2/neu in frozen tumour samples were also amplified when formalin-fixed paraffinembedded tumour samples were used. Similarly, complete concordance was found between frozen and formalin-fixed tissue samples when five tumours without amplification were compared pair by pair.

\section{Concordance of HER2_AMP and HER2_SCO}

A concordance between amplification and HER2_SCO was detected in 86 cases (85\%) when only $3+$ cases were considered positive for HER2_SCO. Six cases with 
Table 2

\begin{tabular}{lccc}
\hline \multicolumn{2}{l}{ Univariate analysis for breast cancer-specific disease-free survival } & & \\
\hline Prognostic factor & $P$ & RR & $95 \%$ Cl \\
\hline Age & n.s. & - & - \\
Menopausal status & n.s. & - & - \\
PT stage & n.s. & 3.35 & $1.77-5.99$ \\
Grade & 0.0002 & - & - \\
Steroid hormone receptor status & n.s. & & - \\
HER2_SCO & n.s. & 3.07 & - \\
HER2_AMP & 0.004 & - & $1.44-6.57$ \\
HER2_ALG & n.s. & 3.27 & $1.40-7.65$ \\
HER2_COM & 0.006 &
\end{tabular}

$\mathrm{Cl}$, confidence interval; n.s., not significant; $\mathrm{RR}$, relative risk.

amplification did not score $3+$, whereas nine $3+$ cases failed to show an amplification. This resulted in a degree of concordance (kappa) of $0.50(95 \% \mathrm{Cl} 0.29-0.72)$.

\section{Sensitivity and specificity of HER2_SCO}

The sensitivity of HER2_SCO 3+ with FISH as reference method was $65 \%$ (11 of 17 amplified cases) and specificity was $89 \%$ (75 of 84 ). Considering also $2+$ cases as positive resulted in an increase in sensitivity to $76 \%$ (13 of 17 amplified cases) with a decreased specificity of $70 \%$ (59 of 84).

\section{Breast cancer-specific DFS}

In univariate analysis (Table 2) neither age at diagnosis nor menopausal status, tumour size or steroid hormone receptor status had a significant influence on the DFS. From the classical prognostic factors only histological grade turned out to be significantly related to DFS ( $P=0.0002$; RR $3.26,95 \% \mathrm{Cl} 1.77-5.99$ ) for DFS. Among the HER-2/neurelated variables, HER2_ALG did not show an influence on DFS, whereas HER2_SCO had a borderline significance $(P=0.059$, RR 1.46, 95\% Cl 0.99-2.16). In contrast, both HER2_AMP $(P=0.004$, RR $3.07,95 \% \mathrm{Cl} 1.44-6.57)$ and HER2_COM ( $P=0.006$, RR $3.27,95 \%$ Cl 1.40-7.65) had a significant influence on the DFS. There was no significant difference in DFS between tumours with low-level amplification (five or six copies per nucleus) and tumours with a higher level of amplification. Three of five and 7 of 12 patients relapsed, respectively. The Kaplan-Meier estimates that yielded significant results are shown in Fig. 1. We then conducted a multivariate Cox regression in a backward fashion. In this Cox regression only histological grade $(P=0.0002, \mathrm{RR} 3.22,95 \% \mathrm{Cl} 1.73-5.99)$ and HER2_AMP $(P=0.026$, RR $2.47,95 \% \mathrm{Cl} 1.12-5.48)$ retained an independent prognostic significance (Table 3 ).

\section{Breast cancer-specific OS}

In univariate analysis (Table 4) neither age at diagnosis nor menopausal status or tumour size had a significant influence on the OS. From the classical prognostic factors only histological grade $(P=0.0003$, RR $4.27,95 \% \mathrm{Cl} 1.96-$ 9.29) and the steroid hormone receptor status $(P=0.012$, RR 0.32, 95\% Cl 0.13-9.78) were significant in univariate analysis for OS. Among the HER-2/neu-related variables, HER2_ALG did not show any influence on OS whatsoever. However, HER2_SCO $(P=0.047, \mathrm{RR} 1.60,95 \% \mathrm{Cl}$ 1.01-2.53) as well as HER2_AMP $(P=0.004, \mathrm{RR} 3.78$, $95 \% \mathrm{Cl} 1.54-9.26)$ and HER2_COM $(P=0.004, \mathrm{RR}$ $4.18,95 \% \mathrm{Cl} 1.60-10.90$ ) had a significant influence on the OS. There was no significant difference in OS between tumours with low-level amplification (five or six copies per nucleus) and tumours with a higher level of amplification. Three of five and 5 of 12 patients died of breast cancer, respectively. The Kaplan-Meier estimates that yielded significant results are shown in Fig. 2. In a multivariate Cox regression analysis only histological grade $(P=0.0007$, RR 3.89, 95\% Cl 1.77-8.55) and HER2_AMP $(P=0.016$, $\mathrm{RR} 3.08,95 \% \mathrm{Cl}$ 1.24-7.67) retained an independent prognostic significance (Table 5).

\section{Discussion}

The prognostic value of HER-2/neu has always been controversial. Studies showing a shorter DFS and/or OS for HER-2/neu-positive patients $[3,18,22,23]$ were opposed by studies which failed to find such an association $[4,5]$. In an earlier series from our department [24] an association with survival was shown only for node-positive, but not for node-negative, breast cancer patients. This association with prognosis in node-positive patients, who are almost uniformly treated with systemic therapy, might be markedly influenced by the ability of HER-2/neu status to affect responsiveness to systemic treatment [11-13]. In any case, the actual role of HER-2/neu as a predictive marker is still 
Figure 1
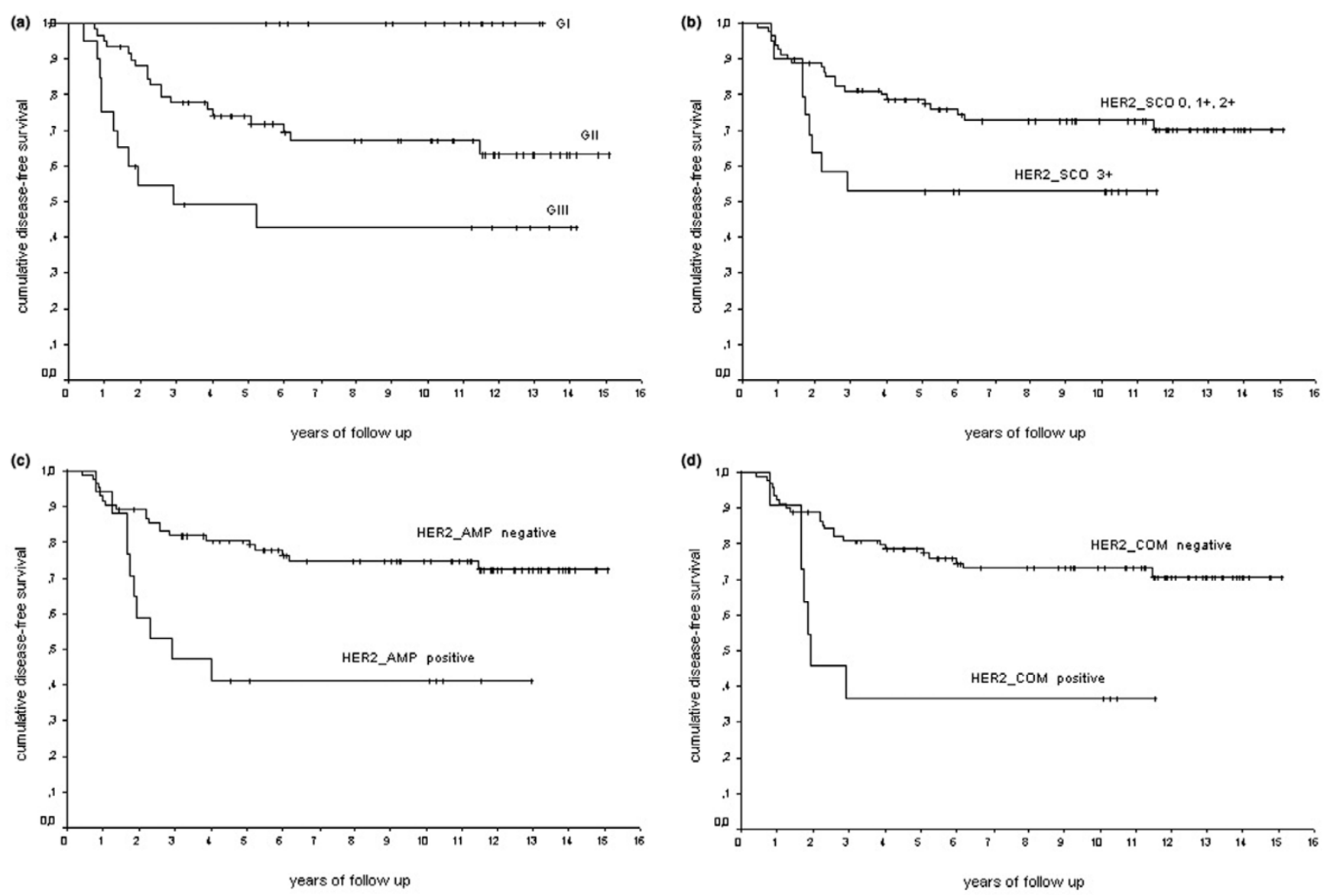

Effect of histological grade, HER2_SCO, HER2_AMP and HER2_COM on disease-free survival. (a) Grade; (b) HER2_SCO; (c) HER2_AMP; (d) HER2_COM.

Table 3

Multivariate analysis for breast cancer-specific disease-free survival

\begin{tabular}{lccc}
\hline Prognostic factor & $P$ & RR & $95 \% \mathrm{Cl}$ \\
\hline Age & n.s. & - & - \\
Menopausal status & n.s. & - & - \\
pT stage & n.s. & - & - \\
Grade & 0.0002 & 3.22 & $1.73-5.99$ \\
Steroid hormone receptor status & n.s. & - & - \\
HER2_SCO & n.s. & 2.47 & - \\
HER2_AMP & 0.026 & - & $1.12-5.48$ \\
HER2_ALG & n.s. & - & - \\
HER2_COM & n.s. & & -
\end{tabular}


Table 4

\begin{tabular}{lccc}
\hline \multicolumn{2}{l}{ Univariate analysis for breast cancer-specific overall survival } & & \\
\hline Prognostic factor & $P$ & RR & - \\
\hline Age & n.s. & - & - \\
Menopausal status & n.s. & - & - \\
pT stage & n.s. & 4.26 & - \\
Grade & 0.0003 & 0.32 & $1.96-9.29$ \\
Steroid hormone receptor status & 0.012 & 1.60 & $0.13-0.78$ \\
HER2_SCO & 0.047 & 3.78 & $1.01-2.53$ \\
HER2_AMP & 0.004 & - & $1.54-9.26$ \\
HER2_ALG & n.s. & 4.18 & - \\
HER2_COM & 0.004 & $1.60-10.90$ \\
\hline
\end{tabular}

$\mathrm{Cl}$, confidence interval; n.s., not significant; RR, relative risk.

a matter of debate [25]. In our present study, we could rule out any such interference of purely prognostic with treatment-related predictive effects because we examined only node-negative patients without any systemic therapy in the adjuvant setting.

When examining the techniques used for the assessment of the HER-2/neu status, gene-based assays almost uniformly confirmed the negative prognostic impact of HER-2/ neu in node-negative patients. Especially in the past few years, FISH has gained considerable interest as a reliable and valid method for determining the HER-2/neu status, confirming its prognostic utility $[18,26]$. Compared with other gene-based assays such as Southern blotting or polymerase chain reaction, FISH is not hampered by dilutional artefacts possibly resulting from a mixture of different cell populations. Similarly to IHC it allows for the specific detection of the alteration in individual cells within the important architectural context. However, in comparison with IHC, FISH is rather time-consuming and leads to substantial costs [27]. It is nevertheless considered the gold standard for assessing HER-2/neu status. A potential advance in the practicability of in situ hybridisation could be the more recently described chromogenic in situ hybridisation, which has shown a good correlation with FISH [28] and an independent prognostic importance in patients with node-negative breast cancer [23].

When determining the amplification of HER-2/neu with $\mathrm{FISH}$ in our cohort of 101 untreated node-negative breast cancer patients, we found $17 \%$ with an amplification of the gene locus. This fraction is largely in line with the literature [18,26,29-31]. The amplification of HER-2/neu measured by FISH showed a significant correlation with the DFS and OS. This strong association between amplification of HER$2 /$ neu and survival of lymph-node-negative breast cancer patients is consistent with previous studies $[18,23,26,30]$.
Only one group could document this association only for OS but not for DFS [32]. Searching for an explanation for their deviating results, the authors speculated that HER-2/ neu might be more a predictive factor for treatment response than a prognostic factor per se because all patients in their study had been treated systemically after relapse.

In contrast with HER-2/neu gene amplification, overexpression of HER-2/neu was not associated with survival in several studies $[4,5,33]$ even though others found a prognostic impact $[22,23,34]$. More recently, Volpi and colleagues [35] found a prognostic significance of HER-2/neu overexpression only for a subgroup of patients with high proliferative activity, whereas they failed to show any prognostic significance of HER-2/neu overexpression in the overall series of node-negative breast cancer patients. These apparent discrepancies have largely prevented the widespread acceptance of HER-2/neu as a prognostic factor in node-negative breast cancer up to now [36].

Several possible reasons could account for these controversial findings. One frequently quoted, simple but nonetheless unsatisfactory reason could be the rather small sample size of several studies. However, a strong and biologically relevant prognostic factor should eventually become evident even within a small sample size. Another possible reason is the remarkable discrepancy in sensitivity between the numerous antibodies used [16] and differences in tissue fixation and processing [37]. However, perhaps the most important reason is the lack of a standardised evaluation protocol in many of the older studies. The standardisation of IHC has become increasingly important since the successful use of trastuzumab (Herceptin $^{\top \mathrm{T}}$ ) in the treatment of HER-2/neu-overexpressing metastatic breast cancer $[17,20,38]$. The United States Food and Drug Administration has approved a standard- 
Figure 2
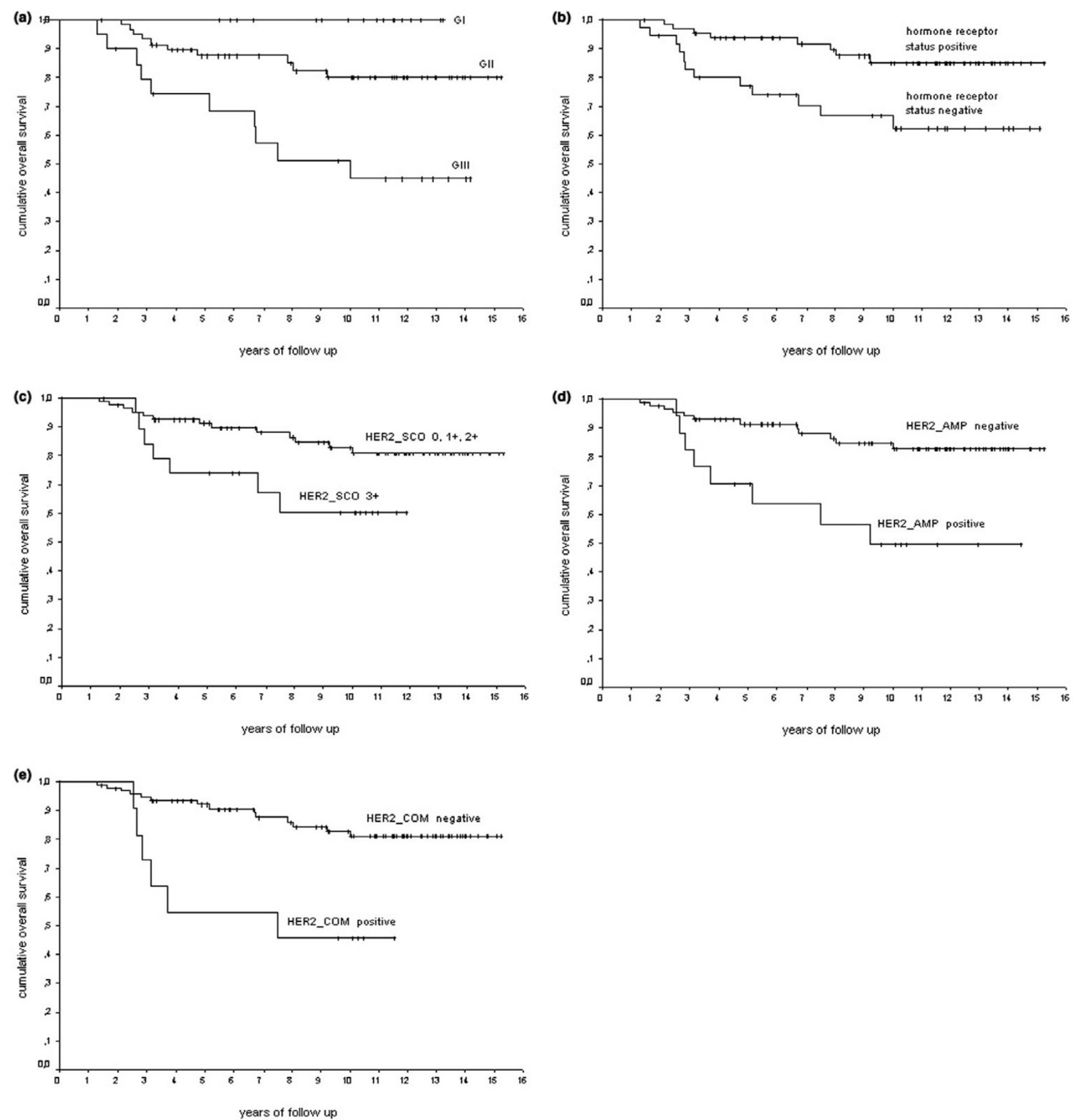

Effect of histological grade, steroid hormone receptor status, HER2_SCO, HER2_AMP and HER2_COM on overall survival. (a) Grade; (b) steroid hormone receptor status; (c) HER2 SCO; (d) HER2 AMP; (e) HER2 COM.

ised IHC kit (HercepTest ${ }^{\mathrm{TM}}$; Dako) with a detailed published scoring system ranging from 0 to $3+$. However, the HercepTest has a rather low specificity, as outlined by Jacobs and colleagues [39]. The studies mentioned above that led to the approval of trastuzumab for HER-2/neu-positive metastatic breast cancer used a cocktail of different antibodies, one of which, the monoclonal antibody CB11, was used in our study. 
Table 5

\begin{tabular}{lccc}
\hline \multicolumn{2}{l}{ Multivariate analysis for breast cancer-specific overall survival } & & RR \\
\hline Prognostic factor & $P$ & - & $95 \% \mathrm{Cl}$ \\
\hline Age & n.s. & - & - \\
Menopausal status & n.s. & - & - \\
pT stage & n.s. & 3.89 & - \\
Grade & 0.0007 & - & $1.77-8.55$ \\
Steroid hormone receptor status & n.s. & - & - \\
HER2_SCO & n.s. & 3.08 & - \\
HER2_AMP & 0.016 & - & $1.24-7.66$ \\
HER2_ALG & n.s. & - & - \\
HER2_COM & n.s. & - \\
\hline
\end{tabular}

$\mathrm{Cl}$, confidence interval; n.s., not significant; RR, relative risk.

When we adapted the scoring system defined for the HercepTest to the CB11 antibody we used in our study, we found a borderline significant correlation with survival.

To our opinion, the concordance between FISH and IHC was only moderate at best with a rate of $85 \%$, even though we regarded only $3+$ cases as overexpressing HER-2/neu. This level of concordance is in line with previously published results [40]. However, others found higher levels of concordance between $\mathrm{FISH}$ and $\mathrm{IHC}$, ranging from $92 \%$ up to $98 \%[39,41,42]$.

When FISH results were compared with IHC data by using computer-assisted image analysis, we showed previously that concordance rates can be significantly improved when the IHC signal is corrected by the subtraction of non-specific cytoplasmic chromogen deposition [43], suggesting that only the strictly membrane-confined IHC signal can be considered truly positive when estimating HER-2/neu IHC slides. However, similarly to our findings others have failed to detect oncogene amplification by FISH in as many as $51 \%$ of tumours with strong $3+$ staining [44]. Because overexpression of HER-2/neu is not necessarily caused only by amplification, polysomy of chromosome 17 has to be taken into account [45]. This polysomy of chromosome 17 could well lead to an incorrect diagnosis of a low-level amplification using single-colored FISH. However, in our study tumours with five or six copies of HER-2/neu had a survival comparable to that of tumours with a higher level of amplification. As a consequence of the moderate concordance, sensitivity and specificity for IHC in our study were lower than described by others $[41,42]$. However, our findings with the frequently used antibody CB11 should not be generalised to $\mathrm{IHC}$ as a whole because different antibodies show well-documented differences in terms of sensitivity and specificity [16].
Cases reported as $2+$ by $\mathrm{IHC}$ should be reassessed with FISH in accordance with the test algorithm used in metastatic breast cancer before the start of a therapy with trastuzumab [21]. To the best of our knowledge we are the first group to use this algorithm to assess the prognosis in node-negative breast cancer patients. The use of this algorithm found 2 of $182+$ tumours amplified and hence increased the percentage of tumours positive for HER-2/ neu to $22 \%$. A similar percentage of HER-2/neu-positive cases has previously been reported when performing FISH only in uncertain cases after IHC with the HercepTest [46]. For these authors, decreases in time and costs were quoted as strong arguments in favour of using this same testing algorithm for the determination of HER-2/neu status.

Because overexpression of HER-2/neu does not necessarily mirror amplification and vice versa, and because both parameters have been correlated with a poor outcome, we investigated whether the combination of amplification and overexpression could be useful in identifying a subgroup of patients with a particularly dismal prognosis. Altogether, 11 tumours showed amplification and overexpression (defined by a score of $3+$ ). Indeed, these patients had a significantly worse prognosis than the remainder of the study cohort. These results are comparable to the data of Sauer and colleagues [31], who also found a markedly adverse prognostic effect in this dual-positive subgroup. Nonetheless, in our multivariate analysis, the combination of both techniques did not add additional prognostic information to that obtained by the amplification alone. However, owing to the relatively small number of events, especially for HER2_COM, subtle differences might be difficult to address adequately.

To assess the clinical relevance of these findings, we included the HER-2/neu-dependent variables 
(HER2 SCO, HER2 AMP, HER2 ALG and HER2 COM) into a multivariate model with the variables tumour size, histological grade and steroid receptor status. These last three variables are commonly accepted for risk assessment in node-negative breast cancer [36]. The factor age (not more than 35 years at diagnosis) was ignored because only one patient in our cohort was younger than 35 . In this multivariate analysis, only histological grade and HER-2/neu amplification were identified as independent prognostic factors for DFS and OS, respectively.

We therefore conclude that HER-2/neu is an independent prognostic factor in node-negative breast cancer, even though its prognostic utility is largely influenced by the method of testing.

To further validate these observations, a prospective study in patients not treated in an adjuvant setting would be desirable. However, this is largely precluded in practice, given the recent consensus recommendations for the treatment of primary breast cancer [36]. For this reason we are currently engaged in a formal meta-analysis of all published studies that have used FISH or chromogenic in situ hybridisation to determine the HER-2/neu status and hope to clarify once and for all the controversial status of HER-2/ neu as a prognostic factor in breast cancer.

\section{Conclusions}

The prognostic significance of HER-2/neu in node-negative breast cancer depends strongly on the method of testing: only the amplification of HER-2/neu is an independent prognostic factor for the long-term prognosis of untreated node-negative breast cancer.

\section{Competing interests}

The author(s) declare that they have no competing interests.

\section{Authors'contributions}

MS planned the study, performed the $\mathrm{IHC}$ and drafted the manuscript. BL performed the in situ hybridisation. CG participated in the statistical analysis. NK participated in the in situ hybridisation. ES, HP, BT and WW participated in defining the study cohort and participated in the IHC. HAL and $\mathrm{HK}$ participated in finally drafting the manuscript. All authors read and approved the final manuscript.

\section{Acknowledgements}

We thank Mrs Christa Krebs and Mrs Christa Reue for helpful assistance and valuable support.

\section{References}

1. Slamon DJ, Clark GM, Wong SG, Levin WJ, Ullrich A, McGurie WL: Human breast cancer: correlation of relapse and survival with amplification of the HER-2/neu oncogene. Science 1987, 235:177-182.
2. Van de Vijver M, Peterse JL, Mooi WJ, Wisman P, Lomans J, Dalesio O, Nusse R: Neu-protein overexpression in breast cancer. Association with comedo-type ductal carcinoma in situ and limited prognostic value in stage II breast cancer. N Engl J Med 1988, 319:1239-1245.

3. Slamon DJ, Godolphin W, Jones LA, Holt JA, Wong SG, Keith DE, Levin WJ, Stuart SG, Udove A, Ullrich A: Studies of the HER-2/ neu proto-oncogene in human breast and ovarian cancer. Science 1989, 244:707-712.

4. Rosen PP, Lesser ML, Arroyo CD, Cranor M, Borgen P, Norton L: Immunohistochemical detection of HER-2/neu in patients with axillary lymph node-negative breast carcinoma. Cancer 1995, 75:1320-1326.

5. Reed W, Hannisdal E, Boehler PJ, Gundersen S, Host H, Marthin $\mathrm{J}$ : The prognostic value of p53 and c-erb-B2 immunostaining is overrated for patients with lymph node-negative breast carcinoma: a multivariate analysis of prognostic factors in 613 patients with a follow-up of 14-30 years. Cancer 2000, 88:804-813.

6. Carlomagno C, Perrone F, Gallo C, De Laurentiis M, Lauria R, Morabito A, Pettinato G, Panico L, D'Antonio A, Bianco AR, et al:: c-erbB2 overexpression decreases the benefit of adjuvant tamoxifen in early stage breast cancer without axillary lymph node metastases. J Clin Oncol 1996, 14:2702-2708.

7. Stal O, Borg A, Ferno M, Kallstrom AC, Malmstrom P, Nordenskjold $B$ : ErbB2 status and the benefit of two or five years of adjuvant tamoxifen in postmenopausal early stage breast cancer. Ann Oncol 2000, 11:1545-1550.

8. Berry DA, Muss HB, Thor AD, Dressler L, Liu ET, Broadwater G, Budman DR, Henderson IC, Barcos M, Hayes D, et al.: HER-2/ neu and p53 expression versus tamoxifen resistance in estrogen receptor-positive, node-positive breast cancer. J Clin Oncol 2000, 18:3471-3479.

9. Elledge RM, Green S, Ciocca D, Pugh R, Allred DC, Clark GM, Hill J, Ravdin P, O'Sullivan J, Martino S, et al.: HER-2 expression and response to tamoxifen in estrogen receptor-positive breast cancer: a Southwest Oncology Group study. Clin Cancer Res 1998, 4:7-12

10. Ellis MJ, Coop A, Singh B, Mauriac L, Llombert-Cussas A, Janicke F, Miller WR, Evans DB, Dugan M, Brady C, et al:: Letrozole is a more effective neoadjuvant endocrine therapy than tamoxifen for erbB-1 and/or erbB-2-positive. Estrogen receptor-positive primary breast cancer: evidence from a phase III randomised trial. J Clin Oncol 2001, 19:3808-3816.

11. Di Leo $A$, Larsimont $D$, Gancberg $D$, Jarvinen $T$, Beauduin $M$, Vindevoghel A, Michel J, Foucan CH, Ries F, Gobert PH, et al.: HER-2 and topo-isomerase II alpha as predictive markers in a population of node-positive breast cancer patients randomly treated with adjuvant CMF or epirubicin plus cyclophosphamide. Ann Oncol 2001, 12:1081-1089.

12. Paik S, Bryant J, Park C, Fisher B, Tan-Chiu E, Hymas D, Fisher ER, Lippmann ME, Wickerham DL, Wolmark N: erbB-2 and response to doxorubicin in patients with axillary lymph node-positive, hormone receptor-negative breast cancer. J Natl Cancer Inst 1998, 90:1361-1370.

13. Moliterni A, Menard S, Valagussa $P$, Biganzoli E, Boracchi $P, B a l-$ sari A, Canalini P, Tomasic G, Marubini E, Pilotti S, et al.: HER2 overexpression and doxorubicin in adjuvant chemotherapy for resectable breast cancer. $J$ Clin Oncol 2003, 21:458-462.

14. Ross JS, Fletcher JA: HER-2/neu (c-erb-B2) gene and protein in breast cancer. Am J Clin Pathol 1999, 112(1 Suppl):S53-S67.

15. Ross JS, Fletcher JA, Linette GP, Stec J, Clark E, Ayers M, Symmans WF, Pusztai L, Bloom KJ: The HER-2/neu gene and protein in breast cancer 2003: biomarker and target of therapy. Oncologist 2003, 8:307-325.

16. Press MF, Hung G, Godolphin W, Slamon DJ: Sensitivity of HER2/neu antibodies in archival tissue samples: potential source of error in immunohistochemical studies of oncogene expression. Cancer Res 1994, 54:2771-2777.

17. Slamon DJ, Leyland-Jones B, Shak S, Fuchs $H$, Paton V, Bajamonde A, Fleming T, Eiermann W, Wolter J, Pegram M, et al.: Use of chemotherapy plus a monoclonal antibody against HER-2 for metastatic breast cancer that overexpresses HER-2. N Engl J Med 2001, 344:783-792.

18. Press MF, Bernstein L, Thomas PA, Meisner LF, Zhou JY, Ma Y, Hung G, Robinson RA, Harris C, El-Naggar A, et al.: HER-2/neu gene amplification by fluorescence in situ hybridisation: eval- 
uation of archival specimens and utility as a marker of poor prognosis in node-negative invasive breast carcinomas. $J$ Clin Oncol 1997, 15:2894-2904.

19. Schmidt M, Bachhuber A, Victor A, Steiner E, Mahlke M, Lehr HA, Pilch $\mathrm{H}$, Weikel W, Knapstein PG: p53 expression and resistance against paclitaxel in patients with metastatic breast cancer. J Cancer Res Clin Oncol 2003, 129:295-302.

20. Cobleigh M, Vogel C, Tripathy D, Robert NJ, Scholl S, Fehrenbacher L, Wolter JM, Paton V, Shak S, Liebermann G, et al:: Multinational study of the efficacy and safety of humanized antiHER-2 monoclonal antibody in women who have HER-2 overexpressing metastatic breast cancer that has progressed after chemotherapy for metastatic disease. J Clin Oncol 1999, 17:2639-2648

21. Di Leo $A$, Dowsett $M$, Horten $B$, Penault-Llorca F: Current status of HER-2 testing. Oncology 2002, 63(Suppl 1):25-32.

22. Press MF, Pike M, Chazin V, Hung G, Udove JA, Markowicz M, Danyluk J, Godolphin W, Sliwkowski M, Akita R, et al:: HER-2/neu expression in node-negative breast cancers: direct tissue quantitation by computerized image analysis and association of overexpression with increased risk of recurrent disease. Cancer Res 1993, 53:4960-4970.

23. Joensuu $H$, Isola J, Lundin M, Salminen T, Holli K, Pylkkänen $L$, Turpeenniemi-Hujanen T, von Smitten K, Lundin J: Amplification of erbB2 and erbB2 overexpression are superior to estrogen receptor status as risk factors for distant recurrence in pT1N0M0 breast cancer: a nationwide population-based study. Clin Cancer Res 2003, 9:923-930.

24. Mitze M, Beck T, Weikel W, Rosenthal H, Knapstein PG: Significance of neu protein for prognosis of breast cancers. Geburtshilfe Frauenheilkd 1990, 50:771-776.

25. Ravdin P: Should HER-2 status be routinely measured for all breast cancer patients? Semin Oncol 1999, 26:117-123.

26. Pauletti G, Dandekar S, Rong $H$, Ramos L, Peng $H$, Seshadri R, Slamon DJ: Assessment of methods for the tissue based detection of the HER-2/neu alteration in human breast cancer: a direct comparison of fluorescence in situ hybridisation and immunohistochemistry. J Clin Oncol 2000, 18:3651-3664.

27. Jacobs TW, Gown AM, Yaziji H, Barnes MJ, Schnitt SJ: Comparison of fluorescence in situ hybridisation and immunohistochemistry for the evaluation of HER-2/neu in breast cancer. $J$ Clin Oncol 1999, 17:1974-1982.

28. Tanner M, Gancberg D, Di Leo A, Larsimont D, Rouas G, Piccart $\mathrm{MJ}$, Isola J: Chromogenic in situ hybridisation: a practical alternative for fluorescence in situ hybridisation to detect HER-2/ neu oncogene amplification in archival breast cancer samples. Am J Pathol 2000, 157:1467-1472.

29. Birner $P$, Oberhuber G, Stani J, Reithofer $C$, Samonigg H, Hausmaninger $H$, Kubista $E$, Kwasny W, Kandioler-Eckersberger $D$, Gnant M, et al.: Evaluation of the United States Food and Drug Administration-approved scoring and test system of HER-2 protein expression in breast cancer. Clin Cancer Res 2001, 7:1669-1675.

30. Onody P, Bertrand F, Muzeau F, Bieche I, Lidereau R: Fluorescence in situ hybridisation and immunohistochemical assays for HER-2/neu status determination. Application to node-negative breast cancer. Arch Pathol Lab Med 2001, 125:746-750.

31. Sauer T, Wiedswang G, Boudjema G, Christensen H, Karesen R: Assessment of HER-2/neu overexpression and/or gene amplification in breast carcinomas: should in situ hybridization be the method of choice? APMIS 2003, 111:444-450.

32. Zemzoum I, Kates RE, Ross JS, Dettmar P, Dutta M, Henrichs C, Yurdseven S, Höfler H, Kiechle M, Schmitt M, Harbeck N: Invasion factors UPA/PAI-1 and HER2 status provide independent and complementary information on patient outcome in nodenegative breast cancer. J Clin Oncol 2003, 21:1022-1028.

33. Harbeck N, Dettmar P, Thomssen C, Berger U, Ulm K, Kates R, Höfler H, Jänicke F, Graeff H, Schmitt M: Risk-group discrimination in node-negative breast cancer using invasion and proliferation markers: 6-year median follow up. Br J Cancer 1999, 80:419-426.

34. Rudolph P, Olsson H, Bonatz G, Ratjen V, Bolte H, Baldetorp B, Fernö M, Parwaresch R, Alm P: Correlation between p53, cerbB-2, and topoisomerase Il $\alpha$ expression, DNA ploidy, hormonal receptor status and proliferation in 356 node-negative breast carcinomas: prognostic implications. J Pathol 1999, 187:207-216.
35. Volpi A, Nanni O, De Paola F, Granato AM, Mangia A, Monti F, Schittuli F, De Lena M, Scarpi E, Rosetti P, et al.: HER-2 expression and cell proliferation: prognostic markers in patients with node-negative breast cancer. J Clin Oncol 2003, 21:2708-2712.

36. Goldhirsch A, Wood WC, Gelber RD, Coates AS, Thulimann B, Senn $\mathrm{HJ}$ : Meeting Highlights: updated international expert consensus on the primary therapy of early breast cancer. $J$ Clin Oncol 2003, 21:3357-3365.

37. Penault Llorca F, Adelaide J, Houvenaeghel G, Hassoun J, Birnbaum $D$, Jacquemier J: Optimization of immunohistochemical detection of ERBB2 in human breast cancer: impact of fixation. $J$ Pathol 1994, 173:65-75.

38. Vogel C, Cobleigh M, Tripathy D, Gutheil JC, Harris LN, Fehrenbacher L, Slamon DJ, Murphy M, Novotny WF, Burchmore M, et al.: Efficacy and safety of trastuzumab (Herceptin) as a single agent in first-line treatment of HER-2 overexpressing metastatic breast cancer. J Clin Oncol 2002, 20:719-726.

39. Jacobs TW, Gown AM, Yaziij H, Barnes MJ, Schnitt SJ: Specificity of HercepTest in determining the HER-2/neu status of breast cancers using the United States Food and Drug Administration - approved scoring system. J Clin Oncol 1999, 17:1983-1987.

40. Lopez-Guerrero JA, Navarro S, Noguera R, Almenar S, Pellin A, Vazquez C, Llombart-Bosch A: Histological tumor grade correlates with HER2/c-erbB-2 status in invasive breast cancer: a comparative analysis between immunohistochemical (CB11 clone and HercepTest) FISH and differential PCR procedures. Arkh Patol 2003, 65:50-55.

41. Couturier J, Vincent-Salomon A, Nicolas A, Beuzeboc P, Mouret E, Zafrani B, Sastre-Garau X: Strong correlation between results of fluorescent in situ hybridization and immunohistochemistry for the assessment of the ERBB2 (HER-2/neu) gene status in breast carcinoma. Mod Pathol 2000, 13:1238-1243.

42. Yaziij H, Goldstein LC, Barry TS, Werling R, Hwang H, Ellis GK, Gralow JR, Livingston RB, Gown AM: HER-2 testing in breast cancer using parallel tissue-based methods. JAMA 2004, 291:1972-1977.

43. Lehr HA, Jacobs TW, Yaziji H, Schnitt SJ, Gown AM: Quantitative evaluation of HER-2/neu status in breast cancer by fluorescence in situ hybridization and by immunohistochemistry with image analysis. Am J Clin Pathol 2001, 115:814-822.

44. Hammock L, Lewis M, Phillips C, Cohen C: Strong HER-2/neu protein overexpression by immunohistochemistry often does not predict oncogene amplification by fluorescence in situ hybridization. Hum Pathol 2003, 34:1043-1047.

45. Lal P, Salazar PA, Ladanyi M, Chen B: Impact of polysomy 17 on HER-2/neu immunohistochemistry in breast carcinomas without HER-2/neu gene amplification. J Mol Diagn 2003, 5:155-159.

46. Falo C, Moreno A, Lloveras B, Figueras A, Varala M, Escobedo A: Algorithm for the diagnosis of HER-2/neu status in breastinfiltrating carcinomas. Am J Clin Oncol 2003, 26:465-470. 